\title{
The influence of contact conditions on surface reaction layers formed between steel surfaces lubricated by an aviation oil
}

\author{
L. Wang*, R.J.K. Wood \\ Surface Engineering and Tribology Group, School of Engineering Sciences, University of Southampton, Highfield, Southampton SO17 1BJ, UK
}

Received 8 November 2006; received in revised form 9 February 2007; accepted 12 February 2007

Available online 16 April 2007

\begin{abstract}
This study focuses on the influence of load and temperature on the formation and stability of tribo-films for bearing steel on bearing steel contacts lubricated with an aviation oil, EXXON Turbo 2380 (TCP based - tricresyl phosphate) at ambient temperatures. Experiments were carried out on a pin-on-disc (POD) tribometer (with a ball-on-flat geometry) under an average loading rate of $0.17 \mathrm{~N} \mathrm{~s}^{-1}$ and sliding speed of $3 \mathrm{~m} \mathrm{~s}^{-1}$. The X-ray photoelectron spectroscopy (XPS) analysis on the worn surfaces of ball and disc shows that a tribo-film forms on both surfaces at room temperature. The formation and removal of the tribo-film are faster on the ball due to the nature of contact between the ball and disc. It was found that the tribo-films formed at room temperature are vulnerable to initial disc temperature. The higher the initial temperature the higher the load carrying capacity. The tribo-film growth and contact deterioration have been monitored by acoustic emission (AE) and electrostatic charge (ESP) sensing systems in real time. The results show that both $\mathrm{AE}$ and ESP can detect the tribo-film and contact breakdown and have great potential for on-line condition monitoring of lubricated tribo-contacts.
\end{abstract}

(C) 2007 Elsevier Ltd. All rights reserved.

Keywords: Tricresyl phosphate; Tribo-film; Aviation oils; Condition monitoring; Acoustic emission; Electrostatic sensing

\section{Introduction}

Tribo-films can form on steel surfaces that are lubricated by oils containing anti-wear additives such as zincdialkldithiophosphates (ZDDP) in automotive lubricants and tricresyl phosphates (TCP) in aviation oils. These films or surface reaction layers can control or reduce wear under boundary lubrication conditions and thus prolong the life of components such as bearings and gears. The study of the mechanisms of TCP started more than 60 years ago when Beeck et al. proposed the Eutectic Theory, in which they suggested that the iron phosphide product can alloy with the iron surface to maintain a polishing action on the lubricated surfaces thus reducing wear [1]. However, it is now widely accepted that the effectiveness of TCP as an anti-wear additive is due to the chemical reactions of phosphorous with iron to form an iron phosphate film

\footnotetext{
*Corresponding author. Tel.: + 442380593 300; fax: + 442380593016 .

E-mail address: ling.wang@soton.ac.uk (L. Wang).
}

or pads. Two possible routes have been proposed [2], i.e. either TCP adsorbs on the metal surface where it reacts directly with metal or other components of the lubricant, or TCP first reacts or decomposes in the lubricant producing products which then react with the metal surface.

Early research into TCP was also focused on the effect of the concentration of TCP in base stocks on its anti-wear properties [3-5]. Since the 1980s, further properties of TCP have been explored including the adsorption/desorption mechanisms and thermal effect $[2,6]$, surface treatment with phosphate esters for wear reduction $[7,8]$ and the importance of corrosive wear when TCP is present [9]. Over the years, ceramics especially silicon nitride have also attracted interest from researchers [10,11]. For silicon nitride and steel contacts, apart from iron phosphate, additional surface layers also form on the silicon nitride surface such as carbonaceous deposits and silicon oxides which effectively reduces the level of wear of silicon nitride. Apart from its anti-wear property, the anti-scuffing or load 
carrying property of TCPs has also been demonstrated $[12,13]$. Compared to the research in ZDDP, the range and quantity of research on TCP are still limited despite the length of time it has been in use.

This study investigates the performance of Exxon Turbo 2380 , a commercially available aviation oil, which contains TCP as the main anti-wear and anti-scuffing additive, under different test conditions to establish load carrying capability at room temperatures. This investigation follows previous studies on the performance of various hard bearing steels and was initiated by bearing and aircraft engine manufacturers who have experienced engine cold start bearing failures and are interested to see the formation and sustainability of tribo-film under low temperatures. Furthermore, the performance of lubricants under cold start conditions is one of the main concerns for the lubricant specialists because wear is at its highest during start-up when the engine surfaces are cold and where an insufficient oil film to separate the surfaces in relative motion to protect surfaces from asperity contact is present [14].

The aims of this study are:

- To investigate the relationship between initial surface temperature and contact rupture load for an oil lubricated steel contact under a constant loading rate and room temperatures.

- To investigate the feasibility of using the novel sensing techniques of acoustic emission (AE) and electrostatic charge (ESP) to monitor growth and damage of the tribo-film and/or contact deterioration for the oil lubricated steel contact.

- To examine the formation and chemical compositions of the tribo-film formed by TCP on the metal surfaces under room temperatures using X-ray photoelectron spectroscopy (XPS) analysis.

AE and ESP sensing techniques are deployed in this study to monitor the physics of contact breakdown and lubricant film deterioration because they can potentially detect different aspects of the contact physics [15] and the combination of two sensing systems in engineering applications such as bearings or gears can help fault diagnosis. Electrostatic sensing is especially sensitive to the tribo-charge generated from wear debris [16], contact potential difference (CPD) [17,18] and chemical interactions within the lubricant [19]. The CPD effect arises from subtle differences in surface work functions especially when surface phase transformation or tribo-film formation or stripping occurs.

AE has been largely used in structural failure detection caused by cracking [20]. Its application to wear mechanisms and manufacturing processes has also been investigated by various researchers [15,21-24]. A great deal of efforts have been made to correlate wear with $\mathrm{AE}$ parameters including $\mathrm{AE}$ amplitude, integrated $\mathrm{AE}$ root mean square (rms), AE counts, hits, rise time, etc. without reaching any universal solutions. In this study, the $\mathrm{AE}$ waveform in the time domain and the power spectral density in the frequency domain are used to analyse the $\mathrm{AE}$ signals and reveal any correlations between contact deterioration and AEs.

\section{Experimental procedure}

Experiments were carried out on a pin-on-disc (POD) tribometer (with a ball-on-flat geometry) under an average loading rate of $0.17 \mathrm{~N} \mathrm{~s}^{-1}(20 \mathrm{~N}$ per $2 \mathrm{~min}$ through step loading) and room temperature (between 20 and $40{ }^{\circ} \mathrm{C}$ ). During testing, a fixed bearing steel ball, $6 \mathrm{~mm}$ in diameter, is loaded against a rotating disc and lubricant is sprayed onto the disc at a rate of $\sim 10 \mathrm{ml} / \mathrm{min}$. Tests under sliding conditions were chosen to simulate engine low load conditions, e.g. during runway taxiing and low thrust operation, where sliding is a factor [25].

A $6.35 \mathrm{~mm}$ diameter M50 bearing steel ball was loaded against an M50NiL bearing steel disc lubricated by Exxon Turbo 2380 oil at a constant sliding speed of $3 \mathrm{~m} \mathrm{~s}^{-1}$. This relatively high speed was used as this is close to the aircraft engine bearing running conditions. A $20 \mathrm{~N}$ load was applied at the beginning of the test, which produced an initial mean Hertzian contact pressure of $1.13 \mathrm{GPa}$, and the load was increased at the rate of $0.17 \mathrm{~N} \mathrm{~s}^{-1}$ by step loading until scuffing occurred (to a maximum $120 \mathrm{~N}$ load or $2.05 \mathrm{GPa}$ mean contact pressure). The loading rate of $0.17 \mathrm{~N} \mathrm{~s}^{-1}$ was chosen in the current study to prevent premature scuffing due to large incremental step loading. The disc was pre-heated to different starting temperatures in the range $20-40{ }^{\circ} \mathrm{C}$ to enable the influence of temperature on the load bearing capacity of the TCP films formed on the metal surfaces to be investigated. The contact friction, linear wear and disc surface temperature together with contact deterioration were monitored using multiple sensors including a strain gauge, an LVDT, an infrared pyrometer, a wideband $\mathrm{AE}$ sensor and an electrostatic wear site sensor in real time. The button-type electrostatic sensor had a $10 \mathrm{~mm}$ diameter flat sensing surface, and was positioned $0.5 \mathrm{~mm}$ above the wear track to monitor tribocharge on the wear track associated with CPD, tribocharging, debris, etc. The AE sensor, a wide-band $(100 \mathrm{kHz}-1 \mathrm{MHz})$ accelerometer from the Physical Acoustic Corporation (PAC), was attached to the ball holder to monitor emissions from wear of the ball or metal-metal tribo-contact. Details of the rig, the sensors and the data acquisition procedure can be found from previous publications $[15,26]$. Raw AE waveforms were captured during the test to enable the analysis in both time and frequency domains. The sampling duration was $6.75 \mathrm{~ms}$ at a sampling rate of $5 \mathrm{MHz}$. The properties of the ball, disc and lubricant are summarised in Table 1.

Tests were started in the mixed elastohydrodynamic lubrication (EHL) or the full-film hydrodynamic lubrication regime with an initial $\lambda$ value between 1.6 and 5.9. The initial $\lambda$ value was calculated using Equations (1)-(3). 
Table 1

Summary of the materials

\begin{tabular}{|c|c|c|}
\hline & M50 ball & M50NiL disc \\
\hline Composition & $\begin{array}{l}0.85 \% \mathrm{C}, 0.30 \% \mathrm{Mn}, 0.20 \% \mathrm{Si}, 4.10 \% \mathrm{Cr} \\
4.25 \% \mathrm{Mo}, 1.00 \% \mathrm{~V}, \mathrm{Fe} \text { remainder }\end{array}$ & $\begin{array}{l}0.13 \% \mathrm{C}, 0.25 \% \mathrm{Mn}, 0.20 \% \mathrm{Si}, 4.20 \% \mathrm{Cr} \text {, } \\
3.40 \% \mathrm{Ni}, 4.25 \% \mathrm{Mo}, 1.20 \% \mathrm{~V} \text {, Fe remainder }\end{array}$ \\
\hline Dimension & $6.35 \mathrm{~mm}$ dia. & $100 \mathrm{~mm}$ dia. $\times 10 \mathrm{~mm}$ thick \\
\hline $\operatorname{Ra}(\mu \mathrm{m})$ & 0.01 & 0.11 \\
\hline Hardness (Hv0.1 kg) & 784 & 793 \\
\hline Young's modulus (GPa) & 205 & 205 \\
\hline $\begin{array}{l}\text { Lubricant: Exxon Turbo } 2380 \\
\text { Kinematic viscosity }\left(\mathrm{mm}^{2} \mathrm{~s}^{-1} \text { or cSt.) }\right.\end{array}$ & $\begin{array}{l}24 \text { at } 40{ }^{\circ} \mathrm{C} \\
4.97 \text { at } 100{ }^{\circ} \mathrm{C}\end{array}$ & \\
\hline Density & $975 \mathrm{~kg} \mathrm{~m}^{-3}$ at $15^{\circ} \mathrm{C}$ & \\
\hline Ingredients & $\begin{array}{l}\text { Synthetic base stock; proprietary performance } \\
\text { additives. } \\
\text { TCP: } 1 \%-5 \% \text {; } \\
n \text {-phenyl-1-naphthylamine: } 1 \%-5 \%\end{array}$ & \\
\hline
\end{tabular}

The oil viscosity has been corrected according to the measured disc surface temperature.

$\lambda=\frac{h_{\min }}{\sqrt{R_{q 1}^{2}+R_{q 2}^{2}}}$,

$\frac{h_{\min }}{R}=1.79\left\{2 \alpha E^{*}\right\}^{0.49}\left\{\frac{\bar{U} \eta_{0}}{2 E^{*} R}\right\}^{0.68}\left\{\frac{W}{2 E^{*} R^{2}}\right\}^{-0.073}$,

$E^{*}=\frac{1-v_{1}^{2}}{E_{1}}+\frac{1-v_{2}^{2}}{E_{2}}$,

where $h_{\min }$ is the minimum film thickness, $R_{q 1}$ and $R_{q 2}$ are the rms roughness of the two contact surfaces, $R$ is the ball radius, $\bar{U}$ is the entrainment velocity, $\alpha$ is the pressure-viscosity index for Exxon Turbo 2380, $E_{1}$ and $E_{2}$ are Young's modulus of ball and disc, $v_{1}$ and $v_{2}$ are Poission's ratio of the two materials and $E^{*}$ is the contact modulus.

Tests were repeated three times under the same test conditions to quantify the repeatability of the results and the error from the repeated tests on the temperature increase, coefficient of friction and linear wear measured by LVDT was less than $5 \%$.

Worn ball/disc surfaces were inspected under a TaiCaan optical three-dimensional profiler to give three-dimensional and two-dimensional wear scar images.

XPS has been the most popular technique for the identification of tribo-films [2,11] by detecting the presence of phosphorous compounds. In this study, selected worn ball and disc samples were cleaned in a cyclohexane ultrasonic bath at room temperature for $15 \mathrm{~min}$ before XPS analysis using the Scienta ESCA-300 at NCESS Daresbury laboratory. An $\mathrm{Al} \mathrm{K} \alpha\left(h_{\mathrm{v}}=1486.6 \mathrm{eV}\right) \mathrm{X}$-ray source was used in all measurements. The slitwidth was set at $1.9 \mathrm{~mm}$ and the take off angle (TOA) was set at $90^{\circ}$ for the scanning. The analysis area was about $1 \mathrm{~mm} \times 0.5 \mathrm{~mm}$, or $0.5 \mathrm{~mm}^{2}$. During the XPS scanning, the whole sample surface area was scanned to ensure the worn part of the surface was covered. C $1 \mathrm{~s}$ binding energy $284.8 \mathrm{eV}$ was

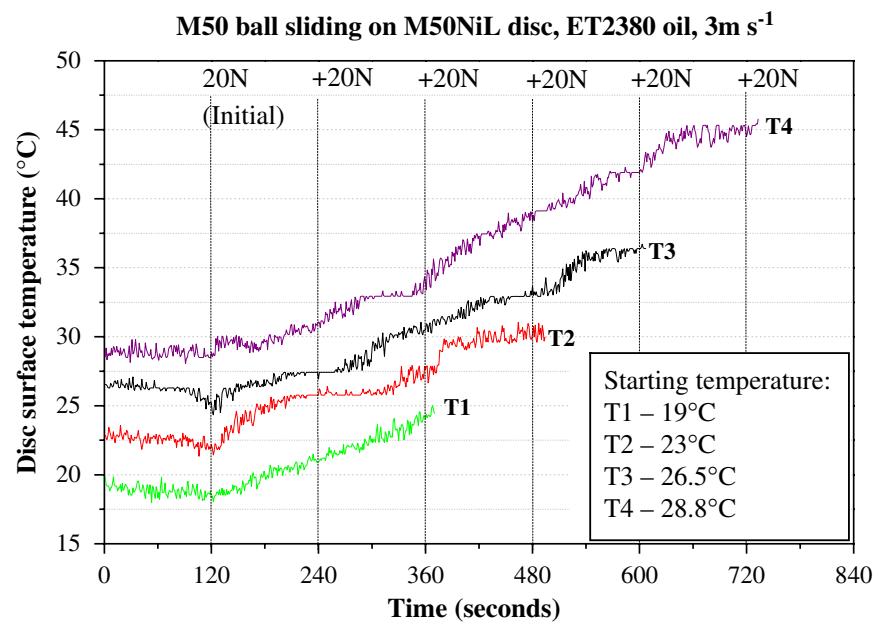

Fig. 1. Effect of disc surface temperature on film rupture at loading rate of $0.17 \mathrm{~N} \mathrm{~s}^{-1}$

used for charge correction. The energy resolution achieved was $\sim 0.4 \mathrm{eV}$. Argon bombardment at $2 \mathrm{kV}$, which removes surface material with a focused ion beam, was used for depth profiling. It is worth mentioning here that only the $\mathrm{Ar}+$ bombarding time is mentioned due to the lack of calibration of the depth. Although this does not give an exact depth of the film, it gives indications of chemical composition change with the depth.

CasaXPS software was used for data analysis. Atomic concentrations of the elements detected are calculated based on normalisation of the detected elements to $100 \%$. Synthetic models and nonlinear-least-squares curve fitting has been applied for chemical state assignment.

\section{Results and discussions}

\subsection{Disc surface temperature}

Fig. 1 shows changes in the disc surface temperature with time for tests which had started at different temperatures 
$19,23,26.5$ and $28.8^{\circ} \mathrm{C}$, which are denoted as $T 1, T 2, T 3$ and $T 4$, respectively. The duration of the tests is 360,480 , 600 and $720 \mathrm{~s}$, respectively. The sliding distances to scuffing are $720,1080,1440$ and $1800 \mathrm{~m}$, respectively. The tests were stopped shortly after scuffing occurred (within $10 \mathrm{~s}$ ) which was detected by high coefficients of friction $(>0.35)$.

The average temperature increase during the tests was $0.025^{\circ} \mathrm{C} / \mathrm{s}$ which caused thermal expansion of the metal disc and ball at an average rate of $0.065 \mu \mathrm{m} / \mathrm{s}$.

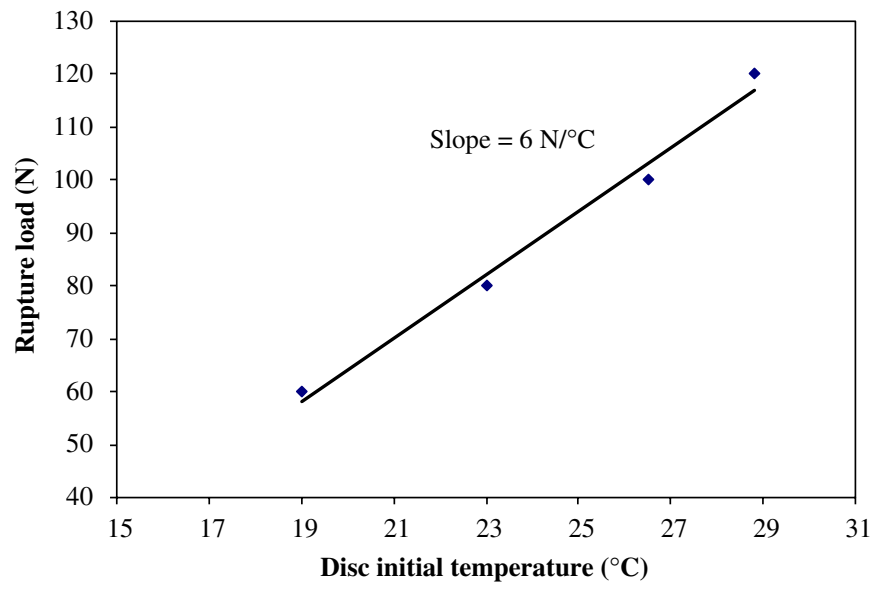

Fig. 2. Linear relationship between the disc initial temperature and the rupture load.
T1 scuffed shortly after $60 \mathrm{~N}$ was loaded. $T 2$ survived the $60 \mathrm{~N}$ load; however, it failed soon after $80 \mathrm{~N}$ was added. $T 3$ and $T 4$, which started at higher temperatures, survived 80 and $100 \mathrm{~N}$, respectively. Fig. 2 shows there is a linear relationship between the initial disc temperature and the rupture load at a rate of $6 \mathrm{~N} /{ }^{\circ} \mathrm{C}$, i.e. an increase of $1{ }^{\circ} \mathrm{C}$ in the initial disc temperature will result in an increase of rupture load of $6 \mathrm{~N}$ for the contact. It is worth stating that this conclusion only stands within the test load range (between 20 and $120 \mathrm{~N}$ ) and the load carrying capacity of the contact will not increase indefinitely with increasing disc surface temperature. Other factors such as oxidation of the lubricant become influential at higher temperatures.

\subsection{Characteristics of the coefficient of friction}

The coefficient of friction over the test duration is shown in Fig. 3 for the four tests. The average dynamic coefficient of friction is 0.1 prior to scuffing for these tests but this suddenly increases to over 0.6 when scuffing occurs. This indicates that the contact conditions appear similar prior to scuffing although tribo-film failure occurred at different loads. The decrease in coefficient of friction with time, especially in $T 4$, may indicate a growth of the tribo-film or change in tribo-film composition which requires further investigation.

M50 ball sliding on M50NiL disc, ET2380 oil, $3 \mathrm{~m} \mathrm{~s}^{-1}$
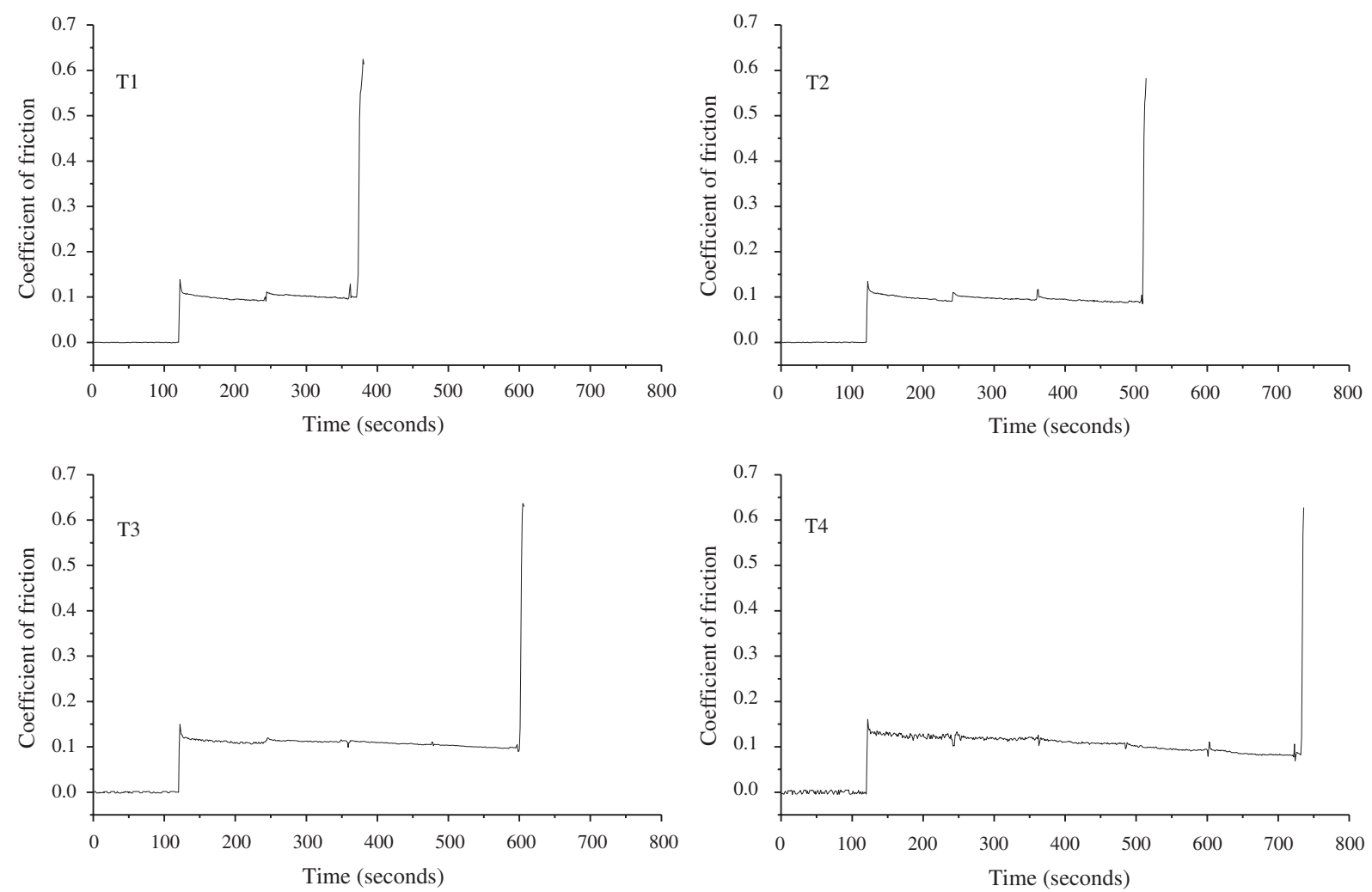

Fig. 3. Characteristics of the coefficient of friction for $T 1$ to $T 4$. 


\subsection{Linear wear rate}

Although the ball and disc have a similar hardness, their wear rates were found to be different due to the contact scenario with the ball being in continuous contact and only part of the disc being in contact at any one time. The results are shown below.

Fig. 4 shows three-dimensional images of ball and disc wear scars from three tests, which ended at different stages, measured using a TaiCaan three-dimensional profiler after testing. The first two tests were carried out at the same sliding speed $\left(3 \mathrm{~m} \mathrm{~s}^{-1}\right)$ under 25 and $40 \mathrm{~N}$ load, respectively. Both tests were run for $1 \mathrm{~h}$ without scuffing. The third test was from $T 3$ (previously discussed) where the contact scuffed when the load reached $100 \mathrm{~N}$. Selected twodimensional scans on each disc are shown in Fig. 5.

The first two tests show that, only the ball was wearing (no wear track was seen on the disc). The only wear seen on

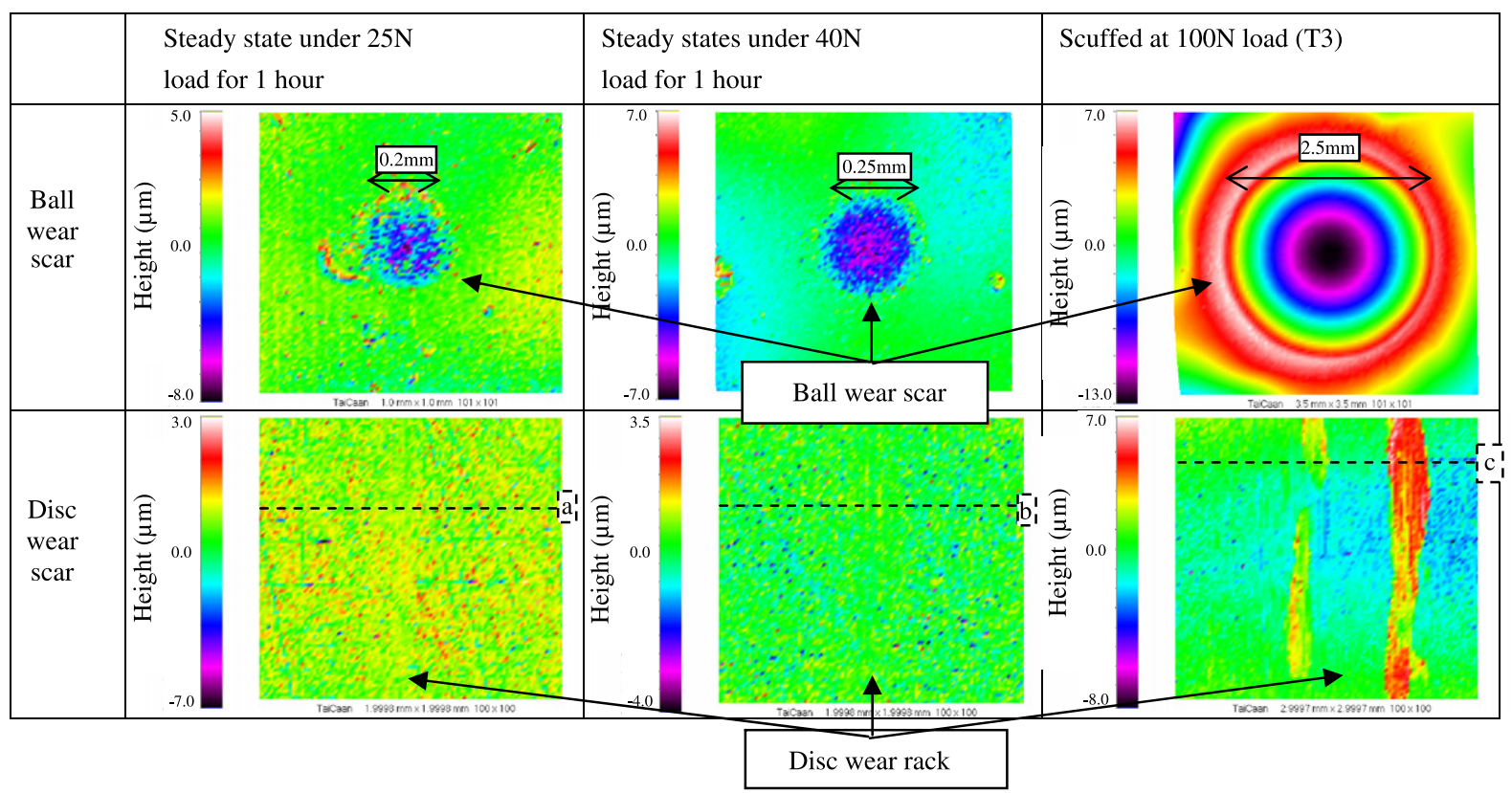

Fig. 4. Three-dimensional images of the ball and disc wear scars at three different stages (note: the ball images shown here are spherical fitted): a, b and c denote the positions where a two-dimensional scan was plotted and shown in Fig. 5 (this figure should be viewed in colour).

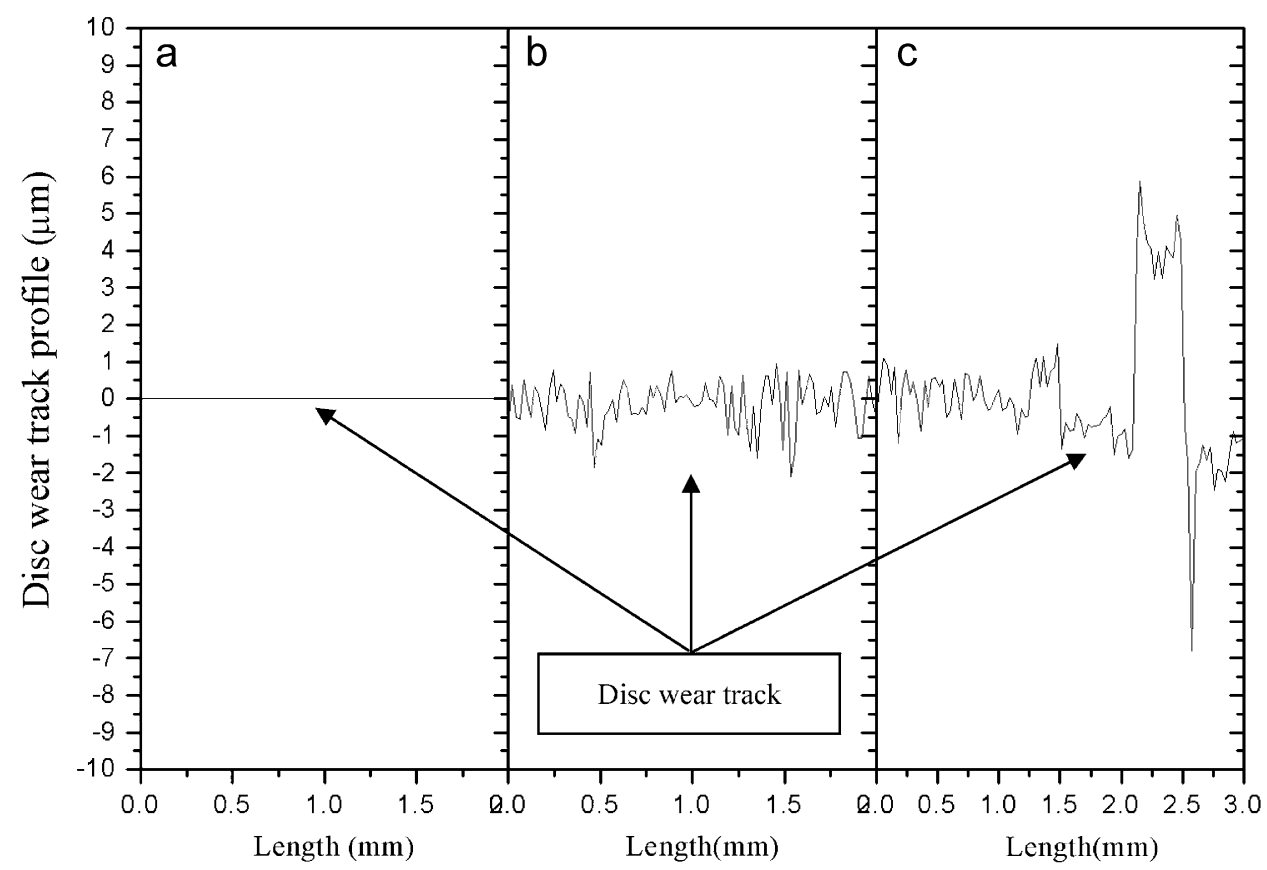

Fig. 5. Two dimensional profiles of the wear track (the positions of traces a-c are shown in Fig. 4). 
M50 ball sliding on M50NiL disc, ET2380 oil, $3 \mathrm{~m} \mathrm{~s}^{-1}$
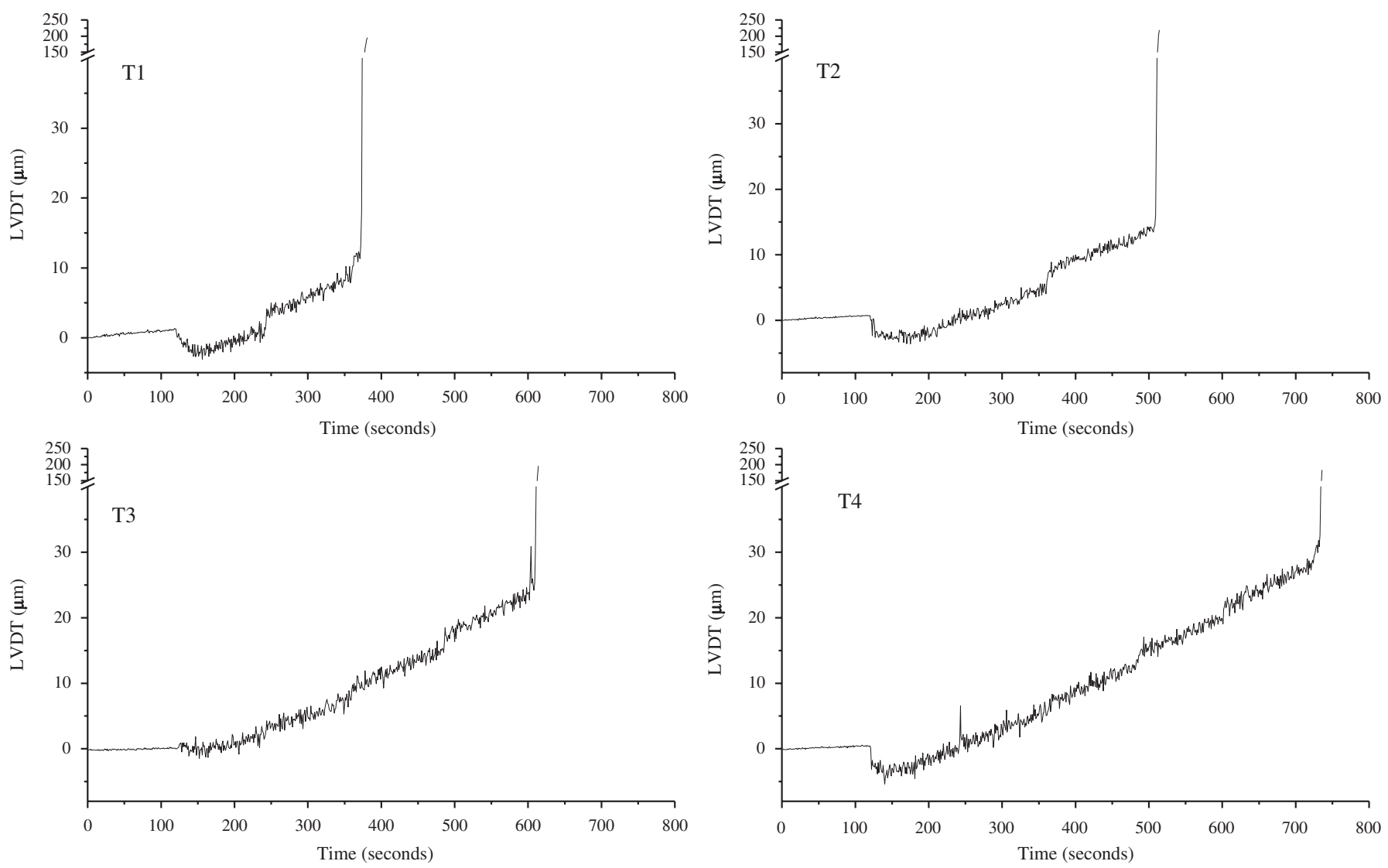

Fig. 6. Wear characteristics (linear wear) for $T 1$ to $T 4$.

Test 3: M50 ball sliding on M50NiL disc load range $20-100 \mathrm{~N}$, sliding speed $3 \mathrm{~m} / \mathrm{s}$

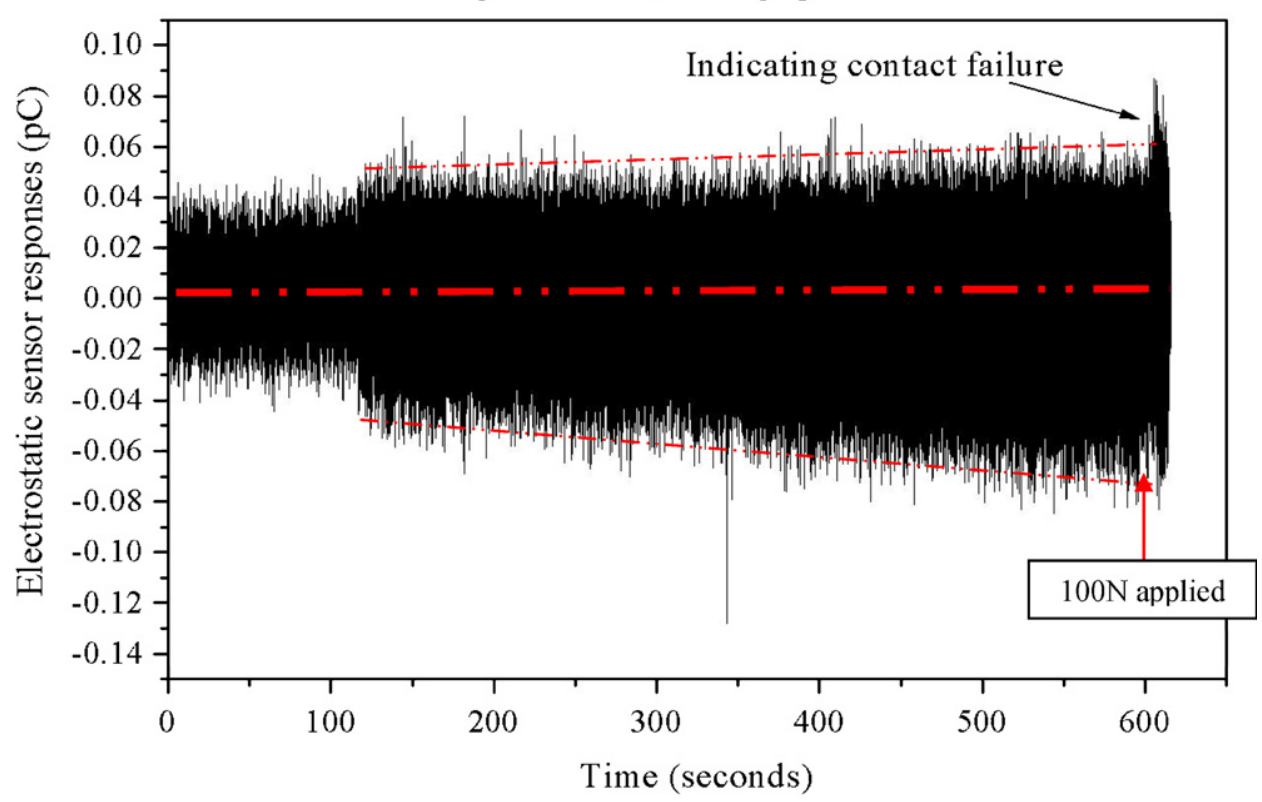

Fig. 7. Electrostatic responses indicating scuffing of the lubricated steel on steel contact. 


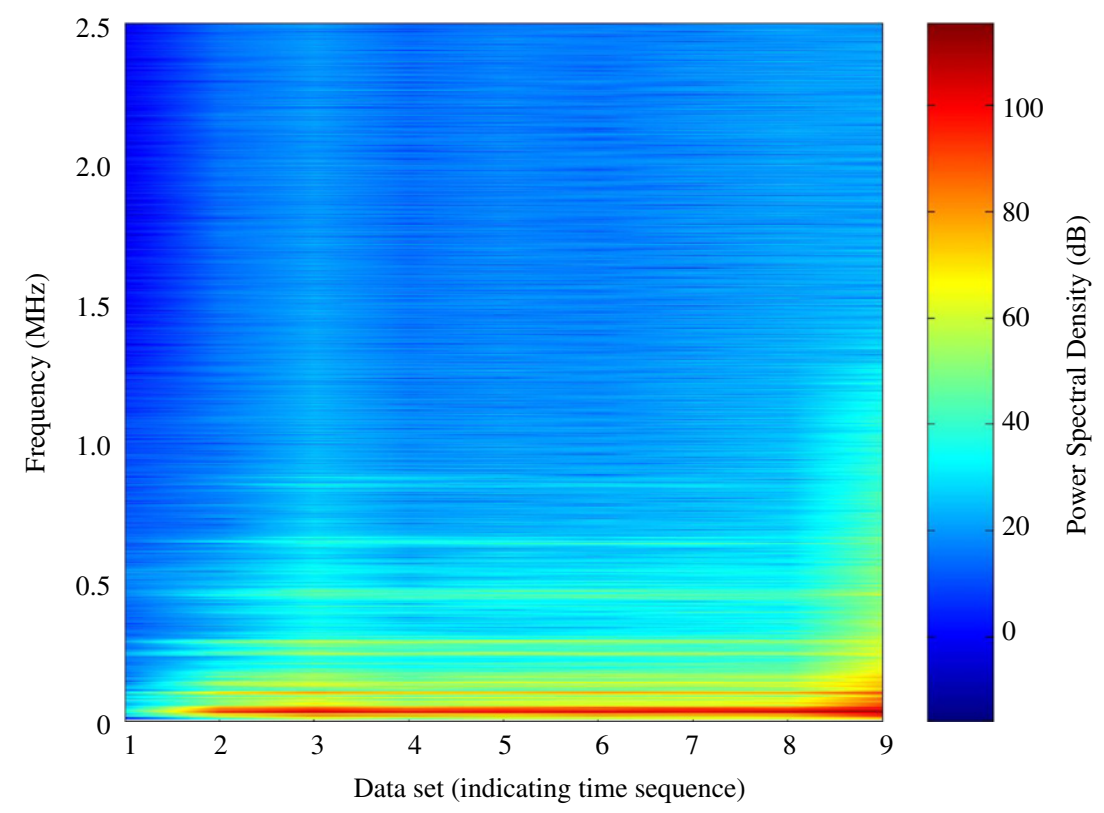

Fig. 8. Colour map of the Acoustic Emission power spectrum indicating contact failure of the steel contact (this figure should be viewed in colour).

Table 2

Details of the AE waveform sampling time

\begin{tabular}{lll}
\hline Sampling point & Test duration (s) & Contact condition \\
\hline 1 & 50 & Background signal \\
2 & 120 & At $20 \mathrm{~N}$ applied \\
3 & 240 & At $40 \mathrm{~N}$ applied \\
4 & 300 & Between 20 and $40 \mathrm{~N}$ \\
5 & 360 & At $60 \mathrm{~N}$ applied \\
6 & 480 & At $80 \mathrm{~N}$ applied \\
7 & 600 & At $100 \mathrm{~N}$ applied \\
8 & 720 & At $120 \mathrm{~N}$ applied \\
9 & 734 & After scuffing \\
\hline
\end{tabular}

the disc was polishing wear. Therefore, the disc wear was negligible before scuffing. On scuffing (T3), a large amount of material is removed from the ball (see Fig. 4). The removed material was adhered onto the disc surface (see track profiles in Fig. 5) and cannot be removed by gentle wiping with solvent. Thus, the linear wear measured by LVDT during the test is mainly from ball wear and the ball linear wear rate was calculated based on the LVDT measurements in this study.

The LVDT traces for $T 1$ to $T 4$, which have been discussed above, are shown in Fig. 6. All four tests show a constant linear wear rate of $0.056 \mu \mathrm{m} \mathrm{s}^{-1}$ or $009 \mu \mathrm{m} \mathrm{m}^{-1}$ of sliding distance at the loading rate of $0.17 \mathrm{~N} \mathrm{~s}^{-1}$. Within seconds of scuffing, the linear (vertical) wear from the ball and disc could be as much as $250 \mu \mathrm{m}$, which means that the ball wear scar increases from less than $0.4 \mathrm{~mm}$ under steady-state wear conditions to more than $2.4 \mathrm{~mm}$ in diameter after scuffing. A very low wear rate of $4 \times 10^{-17} \mathrm{~m}^{3} \mathrm{~N}^{-1} \mathrm{~m}^{-1}$ has been seen for the ball before scuffing, which is in the mild wear regime for lubricated steel contacts.

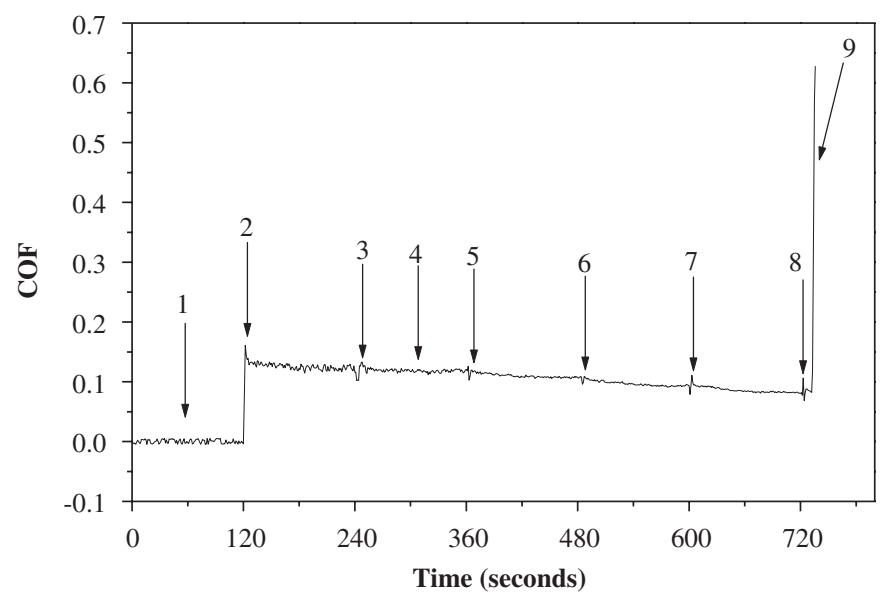

Fig. 9. AE time stream sampling points during $T 4$ (numbers $1-9$ are related to the sample numbers in Fig. 8).

\subsection{Electrostatic sensor responses}

The electrostatic sensing technique has been used in previous studies for wear monitoring where tribo-charging is involved. It is used in this study mainly to detect charges caused by CPD due to phase transformation or tribo-film formation/breakage and debris formation due to material loss from the contact surfaces.

Fig. 7 shows the raw charge signal detected by the electrostatic sensor during T3. During this test, under the constant loading rate, although the linear ball wear rate was constant, the specific wear rate based on ball volume loss was increasing. This also contributes to the increase in charge.

The first $120 \mathrm{~s}$ shows the background signals when the disc was kept stationary. Soon after disc rotation started, a sudden rise in the charge signal was observed. This 

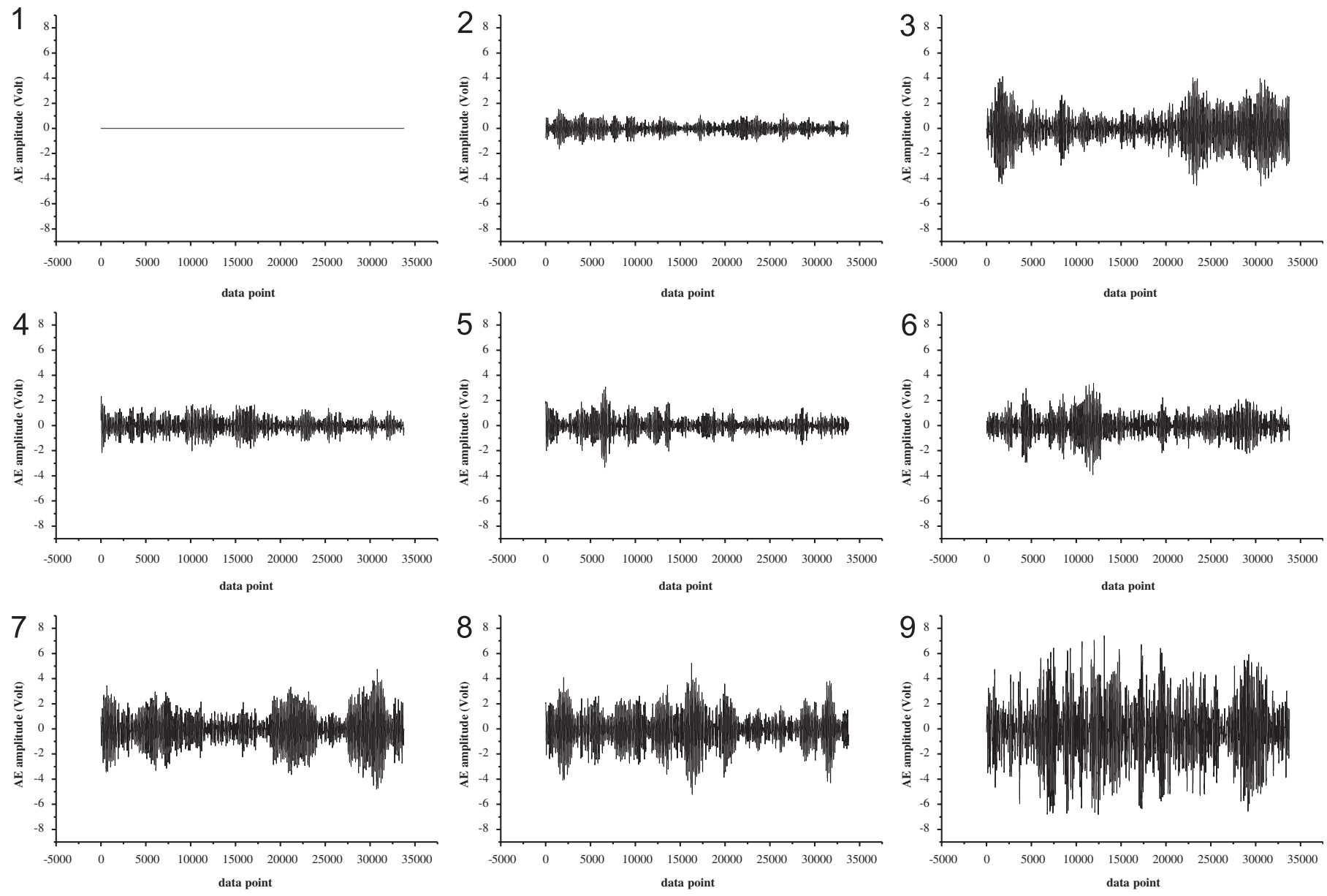

Fig. 10. AE Waveforms from T4.

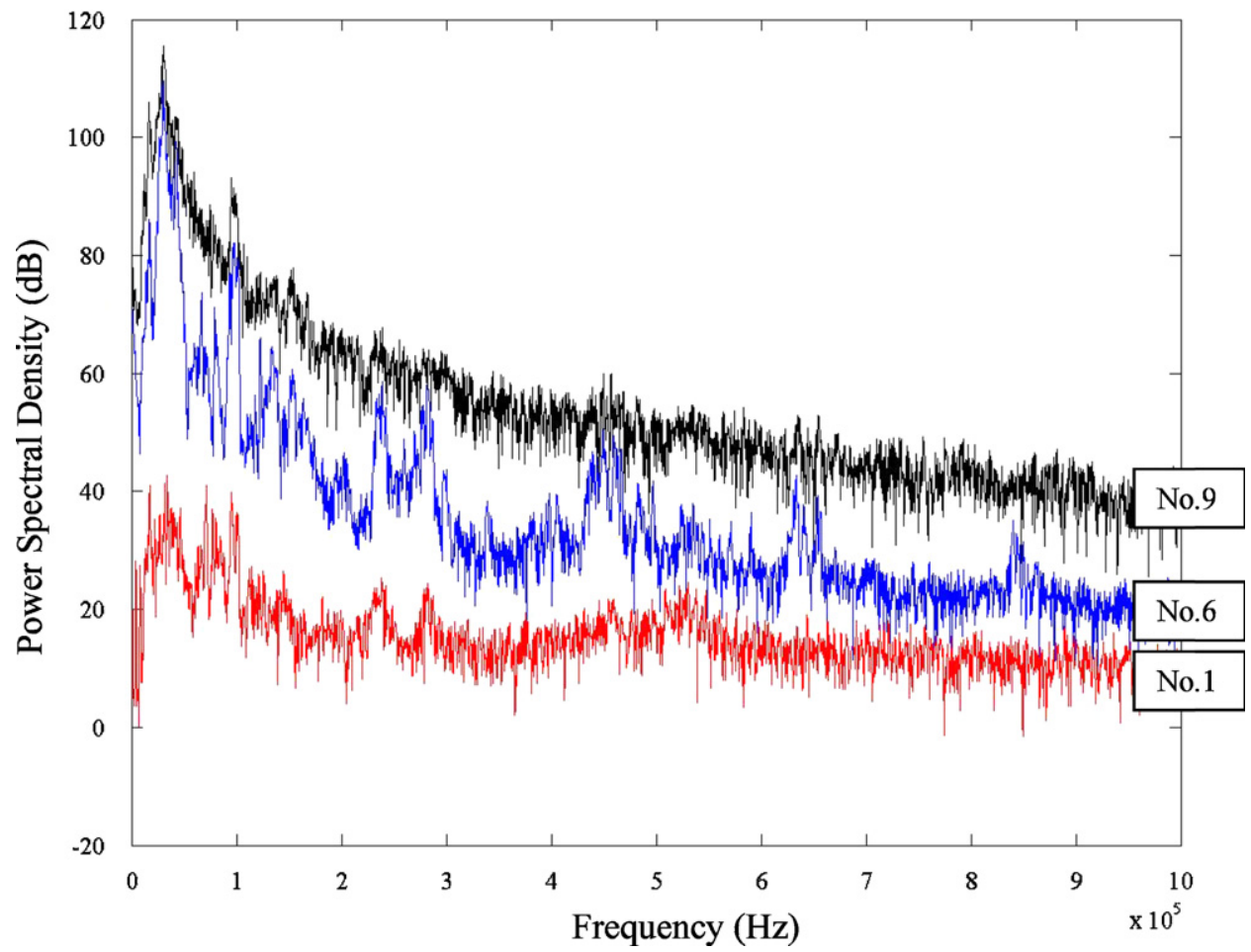

Fig. 11. AE power spectra of points 1,6 and 9 on T4. 
indicates the on-set of tribo-charge on the disc surface due to rubbing between the ball and disc as well as from the shearing within the lubricant film and the disc surface. The charge gradually increased during the test which may be related to the increasing disc surface temperature, the growth of the tribo-film which generates detectable CPD between the tribo-film and the disc, and the wear debris generation. When $100 \mathrm{~N}$ was applied at $600 \mathrm{~s}$, the charge signal showed a continuous positive charge increase from about $0.06 \mathrm{pC}$ to over $0.08 \mathrm{pC}$. This gives a good indication of the contact failure or decay of the tribo-film (also CPD). At this point, charged wear debris piled up outside the wear track on the disc surface (see Fig. 4) will be another main charge source detected by the electrostatic sensor. Similar trends were found in the other three tests.

\subsection{Acoustic emission responses}

The energy from the contact detected by the AE sensor is related to contact conditions. Therefore, AE energy (amplitude and power) is used to monitor contact decay in this study.

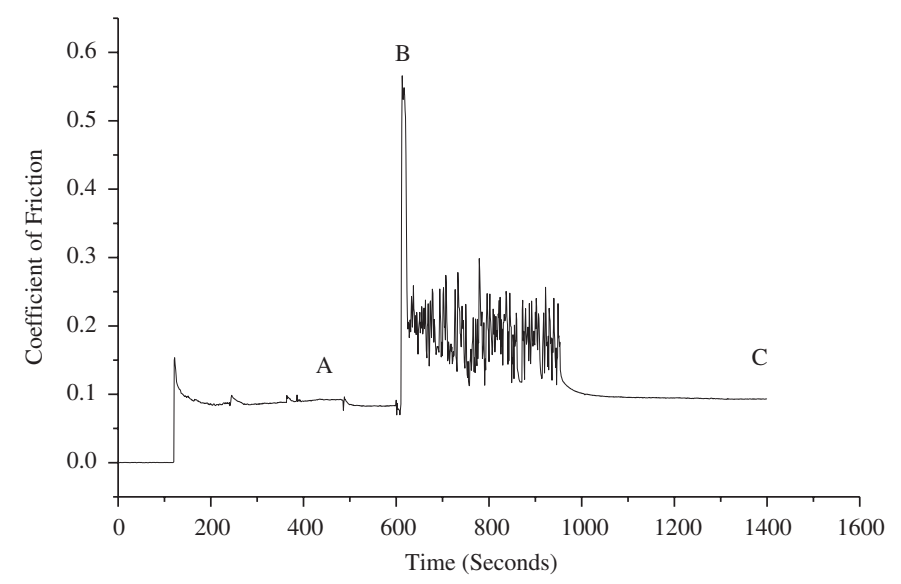

Fig. 12. Patterns of the coefficient of friction, indicating the test stopped at points $\mathrm{A}-\mathrm{C}$.
A typical colour map of the incremental AE power spectrum is shown in Fig. 8 (from T4). Time streams were sampled during the test. Details on sampling points are shown in Table 2 and Fig. 9. Numbers 1-9 are related to the $x$-axis numbering on the colour map in Fig. 8. The corresponding waveforms are shown in Fig. 10.

It can be seen that the waveform amplitudes change from low to high with the progress of the test (from point 1 to 9) apart from at point 3 when $40 \mathrm{~N}$ was applied. This is possibly due to imperfect step loading. Discrete frequency features $(240,290,480,640$ and $860 \mathrm{kHz})$ can be seen at the early stages (points $2-8$, in Fig. 8). However, when steady-state wear changes into scuffing (at point 9), the energy has increased noticeably within a much broader band of frequency $(400 \mathrm{kHz}-1 \mathrm{MHz})$ (see Fig. 11). The previously seen discrete frequencies are thus buried in the high-energy broadband signals. The characteristics of discrete frequencies are possibly due to the removal of asperities from the hard surfaces. At scuffing, the point contact changes to an area contact within seconds which changes the wear mechanisms from asperity level abrasive wear to severe material transfer, adhesive wear and material removal accompanied with high acoustic and frictional energy dissipation.

\subsection{XPS analysis on the worn surfaces}

POD tests were stopped at three different stages according to the on-line friction responses to examine the presence of tribo-films on the worn ball/disc surface using XPS analysis. Tests A, B and C are used to denote the three tests stopped at the steady state (no scuffing has occurred), immediately after scuffing occurred and the steady state experienced after scuffing. Fig. 12 shows the coefficient of friction results from Test C. Tests A and B are also indicated on this graph. Typical ball wear scars for these stages are shown in Fig. 13. It can be seen that the worn surfaces for $\mathrm{A}, \mathrm{B}$ and $\mathrm{C}$ test points are very different. At point A, where no scuffing has occurred, the ball wear scar was very small (diameter less than $0.4 \mathrm{~mm}$, which is

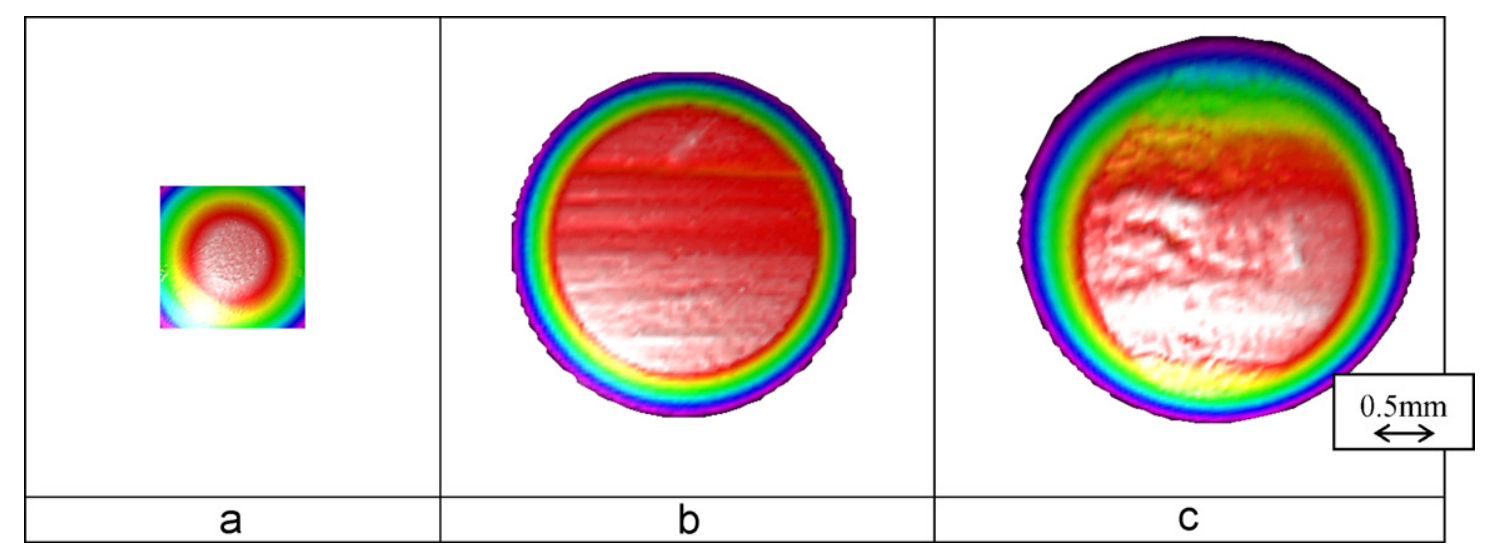

Fig. 13. Ball wear scars from Tests A-C: the top red area or white area in the case of Test A shows the size of the ball scar (this figure should be viewed in colour). 
comparable to the Hertzian diameter of $0.3 \mathrm{~mm}$ at $120 \mathrm{~N}$ load) and the surface was very smooth. At point B, when sudden scuffing occurs, the wear scar had increased 5-6 times and grooves were generated in the wear scar. Similar

Table 3

XPS analysis results: atomic concentrations of the elements detected

\begin{tabular}{llllll}
\hline & & O1s (\%) & C1s (\%) & Fe2p (\%) & P2p (\%) \\
\hline Ball scar & Test A & 35.60 & 57.86 & 5.64 & 0.89 \\
& Test B & 44.08 & 46.36 & 9.22 & 0.34 \\
& Test C & 41.47 & 41.26 & 14.11 & 3.16 \\
\multirow{5}{*}{ Disc scar } & Test A & 50.29 & 31.09 & 18.44 & 0.18 \\
& Test B & 41.76 & 43.14 & 14.35 & 0.75 \\
& Test C & 50.98 & 34.40 & 14.24 & 0.38 \\
\hline
\end{tabular}

features appeared at point $\mathrm{C}$ with a smoother surface plus an incomplete layer of film on top of the metal surface. The chemical compositions show that this layer is a stable tribofilm layer.

Table 3 shows that elemental concentrations of $\mathrm{O}, \mathrm{C}, \mathrm{Fe}$ and $\mathrm{P}$ on both ball and disc scars using XPS analysis. It shows that a phosphorous film is present under all three conditions. The highest concentration of $\mathrm{P} 2 \mathrm{p}$ on the ball appears after scuffing (at point $\mathrm{C}$ ) and on the disc it appears at scuffing (at point B). Also, it is high on the ball before scuffing (at point A) and reduces immediately after scuffing (at point B) suggesting the tribo-film forms and ruptures more quickly on the ball than on the disc. The fact that the ball is in continuous contact and the disc is in intermittent contact results in higher ball surface a

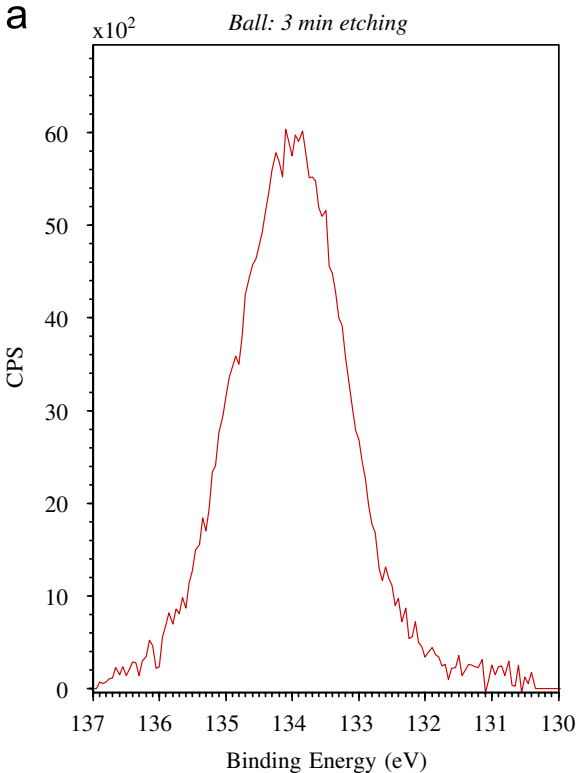

d

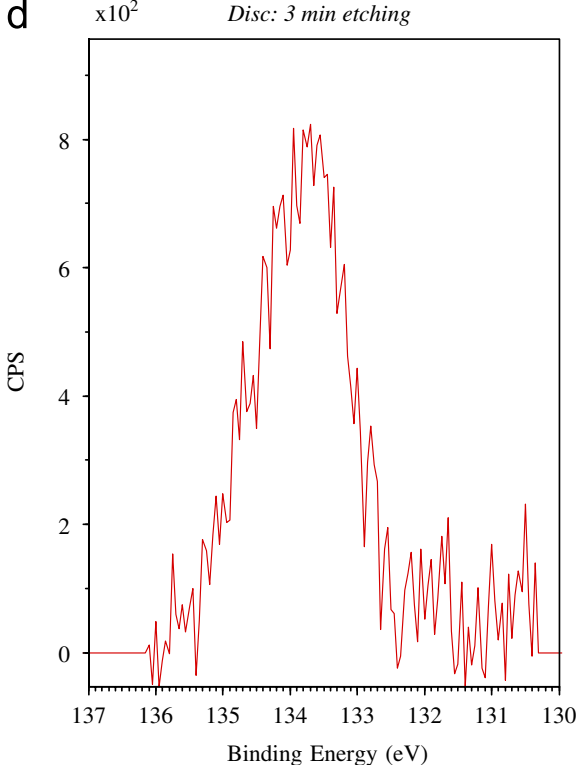

b

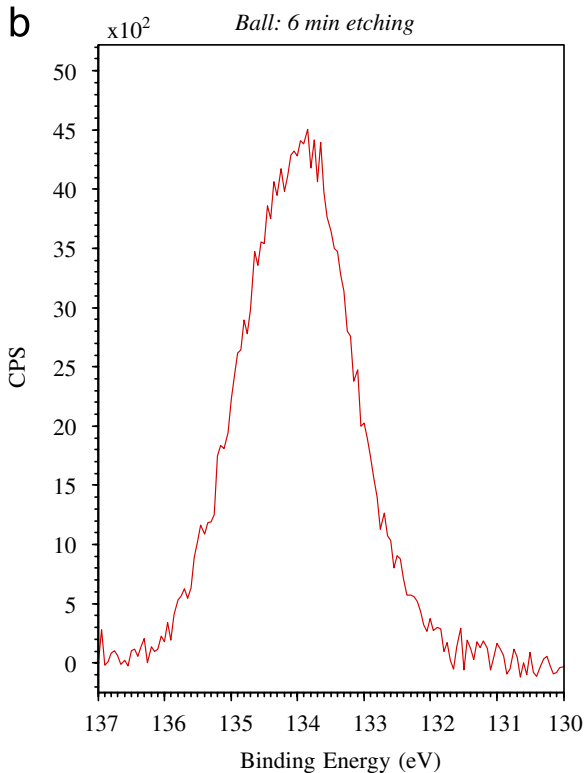

e

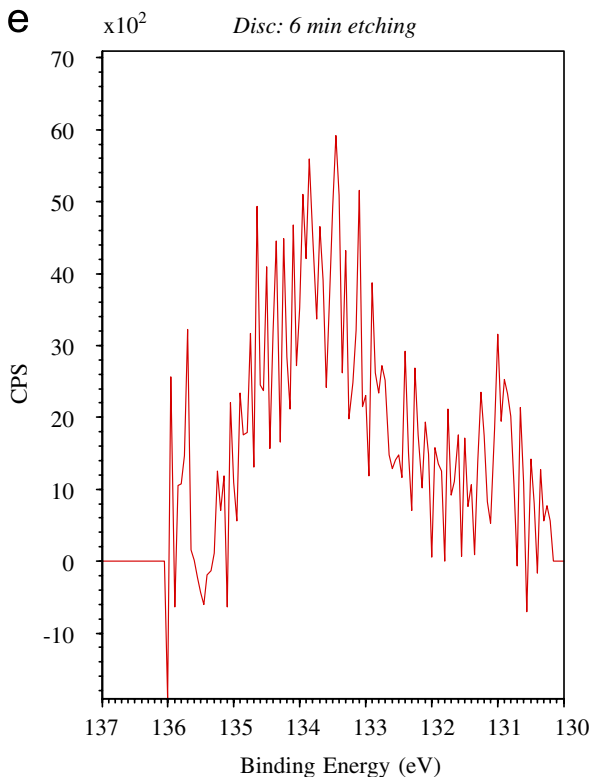

C

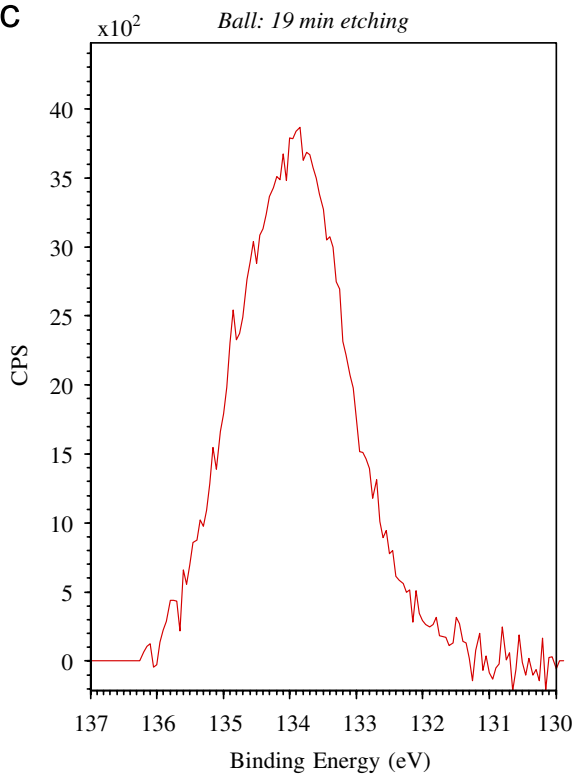

$f$

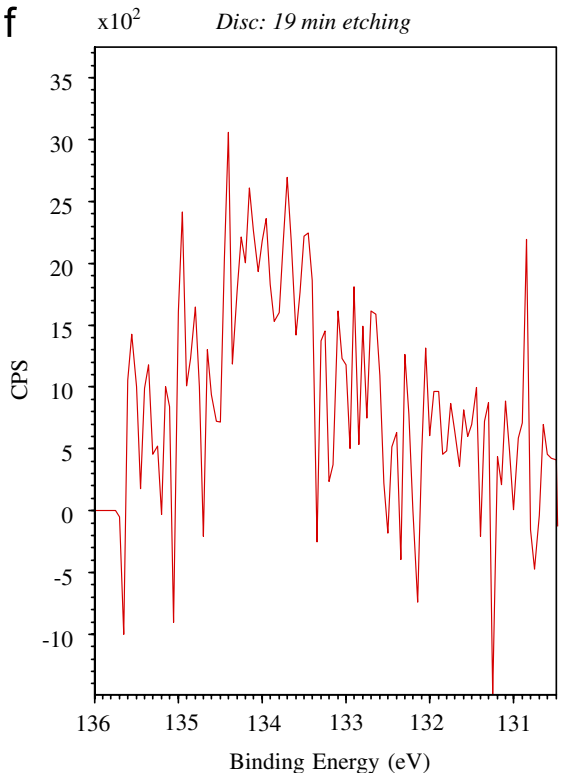

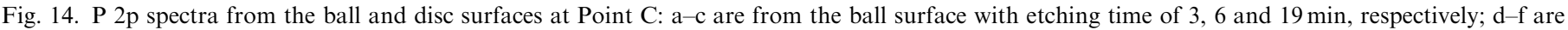
from the disc surface with etching time of 3,6 and $19 \mathrm{~min}$, respectively. 
temperatures. Also, the estimated contact temperature within the contact area is much higher than the measured disc surface temperature. Based on the Hirst and Moore model [27], at the beginning of $T 1$, when the $20 \mathrm{~N}$ load was applied, although the disc temperature was measured as $19^{\circ} \mathrm{C}$, a rise of over $40^{\circ} \mathrm{C}$ within the contact area was estimated. This could have promoted the growth of a tribofilm under the test conditions. The high $\mathrm{P}$ concentration on the ball after scuffing (point C) is due to the fact that the contact had gone through the worst situation (high temperature, friction and wear) and a more stable and uniformed tribo-film had formed protecting the surface from further damage. Placek and Shankwalkar also found that TCP only produces significantly thick films on steel at temperatures greater than $250^{\circ} \mathrm{C}$ [14]. The tribo-film formed at room temperature can protect the contact to a certain extend depending on the sliding speed, temperature and loading conditions.

The depth profiling results of the tribo-film on both the ball and disc surfaces at Point $\mathrm{C}$ are shown in Fig. 14. Three etchings (3, 6 and $19 \mathrm{~min}$ ) were carried out on the ball and disc samples. The phosphorous films on the ball and the disc are different with the main content of about 133 and $132 \mathrm{eV}$, respectively. The chemical nature of the films (compositions) hardly changes with the depth for either the ball or the disc surfaces. However, further detailed analysis of the XPS spectra by curve fitting the spectra is required and will be the subject of future work.

\section{Conclusions}

The results have shown that the TCP tribofilm formation starts on the commencement of sliding even at room temperature which is sufficient in protecting the contact. A more stable film can form at much higher temperatures.

The results show that the original disc surface temperature plays an important role in their sustainability under loading. The tribofilm survived at higher loads as the original disc surface temperature was increased at a rate of $6 \mathrm{~N} /{ }^{\circ} \mathrm{C}$ for the load range (under $120 \mathrm{~N}$ ) tested in this study.

The linear wear monitored by an LVDT and the coefficient of friction levels monitored by a strain gauge in real time suggest that the wear mechanism did not change before scuffing and when the tribofilm is present minimal wear rates were measured.

Both AE and ESP sensing systems gave good indications of contact failure. As the metal contact scuffs, the increase in the raw ESP signal (from 0.06 to $0.08 \mathrm{pC}$ ) is due to the damage of the thin tribo-film (CPD) on the disc surface and the wear debris generated. The AE waveform changes from a continuous signal to a burst type signal during the test but changes to a continuous signal, with exceptionally large amplitude, when scuffing occurs. Also, the AE discrete frequencies changed to broadband at much higher energy levels on scuffing.
The presence and chemical composition of surface reaction layers have been identified by XPS. Tribo-films containing phosphates have been found on both ball and disc surfaces. A more stable and uniform phosphorous film has formed on the ball after scuffing. Depth profiles from XPS show that the composition of the tribofilm does not change with the depth.

\section{Acknowledgements}

The authors would like to express their sincere acknowledgement to Mr. Edgar Streit and Dr. Oskar Beer from FAG, Schweinfurt, Germany, for their generous support of the test materials. The authors would also like to acknowledge EPSRC in funding the XPS analysis at NCESS Daresbury laboratory (Grant ref. EP/E025722/1), and providing Southampton University the TaiCaan three dimensional profiler from the loan pool.

\section{References}

[1] Beeck O, Givens JW, Williams EC. On the mechanism of boundary lubrication. II. Wear prevention by addition agents. Proc Roy Soc (London) A Math Phys Sci 1940;177(968):103-18.

[2] Wheeler DR, Faut OD. The adsorption and thermal decomposition of tricresylphosphate (TCP) on iron and gold. Appl Surf Sci 1984; 18:106-22.

[3] Cottington RL, Ravner H. Neopentyl polyol esters for jet engine lubricants - effect of tricresyl phosphate on thermal stability and corrosivity. Wear 1968;12(4):300.

[4] Godfrey D. Lubrication mechanism of tricresyl phosphate on steel. ASLE Trans 1965;8:1-11.

[5] Bieber HE, Klaus EE, et al. Study of tricresyl phosphate as additive for boundary lubrication. ASLE Trans 1968;11(2):155-61.

[6] Ghose HM, Ferrante J, et al. The effect of tricresyl-phosphate (TCP) as an additive on wear of iron (Fe). Report No. NASA TM-100103: National Aeronautics and Space Administration Lewis Research Center, Cleveland, $\mathrm{OH}$ 44135; 1987. 15 p.

[7] Placek DG, Shankwalkar SG. Phosphate ester surface treatment for reduced wear and corrosion protection. Wear 1994;173:207-17.

[8] Arezzo F, Moore RL. Reactions between 52100 steel and tricresyl phosphate neat and mixed with hydrocarbon oil. Surf Coat Technol 1987;33:235-42.

[9] Gauthier A, Montes H, Georges JM. Boundary lubrication with tricresylphosphate: importance of corrosive wear. ASLE 1981;25(4): $445-55$.

[10] Wu WT, Duda JL, Klaus EE. Lubrication studies with alumina-onalumina, steel-on-steel, and steel-on-alumina bearing systems. J Am Ceram Soc 1990;73(8):2247-54.

[11] Liu W, Klaus EE, Duda JL. Wear behaviour of steel-on-Si3N4 and Si3N4-on-Si3N4 systems with vapour phase lubrication of oleic acid and TCP. Wear 1998;214:207-11.

[12] Yamamoto Y, Hirano F. The effect of the addition of phosphate esters to paraffinic base oils on their lubricating performance under sliding conditions. Wear 1982;78(3):285-96.

[13] Ma Y, Liu J, et al. The effect of oxy-nitrided steel surface on improving the lubricating performance of tricresyl phosphate. Wear 1997;210(1-2):287-90.

[14] Placek DG, Shankwalkar SG. Phosphate ester surface treatment for reduced wear and corrosion protection. Wear 1994;173:207-17.

[15] Sun J, Wood RJK, Wang L, et al. Wear monitoring of bearing steel using electrostatic and acoustic emission techniques. Wear 2005; 259:1482-9. 
[16] Harvey T, Morris S, et al. Real-time monitoring of wear debris using electrostatic sensing techniques. Proceedings of the Institution of Mechanical Engineers, Part J. J Eng Tribol 2007; 221(J1):27-40.

[17] Tasbaz OD, Wood RJK, et al. Electrostatic monitoring of oil lubricated sliding points contacts for early detection of scuffing. Wear 1999;23(1):86-97.

[18] Morris S, Wood RJK, et al. Use of electrostatic charge monitoring for early detection of adhesive wear in oil lubricated contacts. Trans ASME 2002;124:288-96.

[19] Booth JE, Nelson KD, et al. The feasibility of using electrostatic monitoring to identify diesel lubricant additives and soot contamination interactions by factorial analysis. Tribol Int 2006;39:1564-75.

[20] Williams JH, Delonga DM, Lee SS. Correlations of acoustic emission with fracture mechanics parameters in structural bridge steels during fatigue. Mater Eval 1982;40(11):1184-9.

[21] Tse MK, Briggs JC. In-process tool wear sensing by acoustic emission. Proceeding of the 11th world conference on non-destructive testing, volume 1. Columbus, OH: American Society for NonDestructive Testing; 1985. p. 70-7.

[22] Kannatey-Asibu E, Dornfeld A. A study of tool wear using statistical analysis of metal-cutting acoustic emission. Wear 1982;76:247-61.

[23] McBride SL, Boness RJ, et al. Acoustic emission from lubricated and unlubricated rubbing surfaces. J Acoust Emission 1989;8(1-2):192-7.

[24] Boness RJ, McBride SL, Sobczyk M. Wear studies using acoustic emission techniques. Tribol Int 1990;23(5):291-5.

[25] Wang L, Wood RJK, et al. Performance evaluation of hybrid (ceramic on steel) bearings with advanced aircraft engine oils for lubrication. Proceedings of ASME turbo expo 2004, Power for land, sea, and air, June 14-17, Vienna, Austria, 2004. p. 117-26.

[26] Wang L, Wood RJK, et al. Wear performance of oil lubricated silicon nitride sliding against various bearing steels. Wear 2003;255:657-68.

[27] Hirst W, Moore AJ. The effect of temperature on traction in elastohydrodynamic lubrication, Philos Trans Roy Soc London. Ser A, Math Phys Sci 1980;298(1438):183-208. 